\title{
Fractured penis in a patient taking sildenafil and warfarin
}

\author{
Nicholas E. Nacca $\cdot$ Brian T. Kloss
}

Received: 28 July 2010 / Accepted: 1 September 2010 / Published online: 16 October 2010

(C) The Author(s) 2010. This article is published with open access at Springerlink.com

This case of penile fracture is unique as it involves a patient taking both sildenafil and warfarin, one drug that potentiates the risk of a penile fracture and a second drug that makes the degree of bleeding and hematoma worse.

A 46-year-old circumcised male was sent to the Emergency Department by his primary care physician 1 day after hearing a "pop" during sexual intercourse. He reported an immediate loss of erection, left-sided penile swelling giving the penis a bent appearance, and a bloody meatal discharge. Over the following $24 \mathrm{~h}$, he developed scrotal edema and ecchymosis (Fig. 1). He maintained the ability to micturate and denied pain. His medical history was significant for CVA and DVT, and he takes warfarin daily. The CVA resulted in hemiparesthesia; therefore, he uses sildenafil prior to intercourse.

Vital signs were normal, and physical examination revealed tenderness on palpation of the pubic symphysis, profound ecchymosis, and edema extending from the lower abdomen to the perineum with absence of external injury. His INR was 1.9, which was reversed with 5 units of fresh frozen plasma given to the patient prior to being taken to the operating room.

Penile fractures were responsible for approximately 1,000 hospital admissions in the US in 2006. The average age of patients is 36 , with Caucasians making up the largest demographic [1]. A penile fracture is a traumatic rupture of the tunica albuginea of the corpus cavernosum following direct blunt trauma [2]. An estimated $20 \%$ of patients have a concomitant urethral injury [1]. The diagnosis of penile

\section{N. E. Nacca $\cdot$ B. T. Kloss $(\square)$}

Department of Emergency Medicine,

SUNY Upstate Medical University,

550 East Genesee Street, Syracuse, NY 13202, USA

e-mail: klossb@upstate.edu

N. E. Nacca

e-mail: naccan@upstate.edu fracture is based on clinical grounds and is a urological emergency requiring immediate surgical consultation [3]. Penile fracture has been reported in correlation with sildenafil use; however, it is unclear whether the relationship is causational [4].

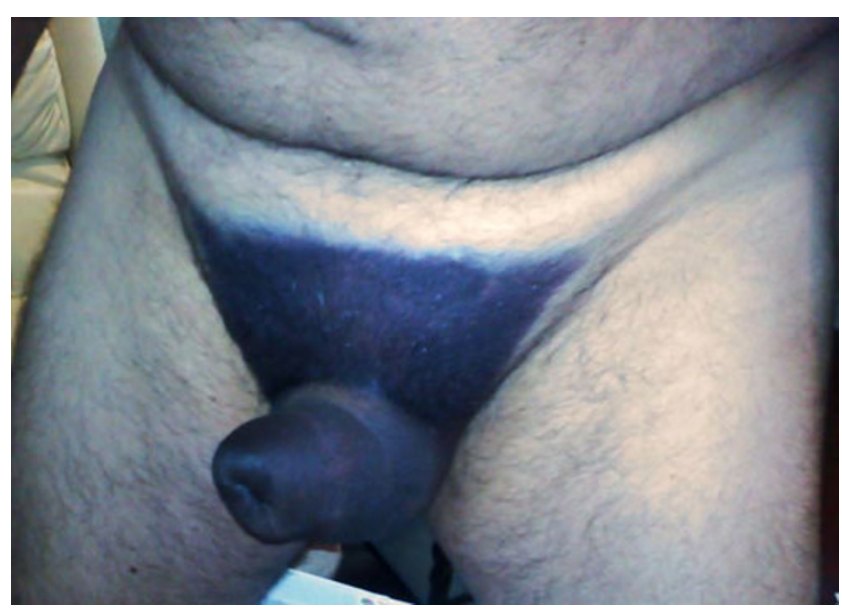

Fig. 1 An image of the patient taken the day of his presentation to the emergency department

Open Access This article is distributed under the terms of the Creative Commons Attribution Noncommercial License which permits any noncommercial use, distribution, and reproduction in any medium, provided the original author(s) and source are credited.

\section{References}

1. Aaronson DS, Schindel AW (2010) National statistics on penile fracture. J Sex Med 7(7): 3226

2. Orvis BR, Mc Aninch JW (1989) Penile rupture. Urol Clin North Am 16(2):369-375

3. Al-Shaiji TF, Amann J, Brock GB (2009) Fractured penis: Diagnosis and management. J Sex Med 6: 3231-3240

4. Blake SM, Bowley DMG, Dickinson A (2010) Fractured penis: another complication of sildenafil. Grand Rounds (2): 11-12, http:// www.grandrounds-e-med.com/articles/gr2001-020-print.pdf 